\title{
The Three Faces of Mad Men \\ Middlebrow Culture and Quality Television
}

Melissa Jane HaRdie

UNIVERSITY OF SYDNEY

—THE REJUVENATOR

An association between pleasure and the machine anchors the eleventh episode of Mad Men's first season. Peggy Olsen is tasked with writing copy for a weight-loss contraption (the Rejuvenator) that she discovers operates more efficiently as a vibrator. A distant goal of reduction is supplanted by a more immediate satisfaction and amplification. Her slogan, 'You'll Love the Way It Makes You Feel', alludes to the potential for pleasure the Rejuvenator holds, substituting feeling, and positive feelings at that, for the purported function of the device, streamlining the disciplinary regime of bodily reduction. The Rejuvenator models temporal reversion as the euphemistic pretext for self-pleasure: rejuvenation re-engineers a nostalgic version of the past as a future event.

Within the parameters of a period drama this modelling has the collateral effect of demarcating Mad Men's modus operandi as typically modernist, a utopian streamlining of history with incidental benefit for current pleasures. At the same time it offers a frame for the series itself as a form of nostalgic revision that pits 
representations of the sluggish or reactionary past against its own modernising propaganda. It introduces feminine sexual pleasure as a metonym for the aesthetic, identifying another concern mid-century, the market dominance of certain kinds of women's texts, and instating an allegory for the contemporary place of twenty-first century 'quality' television and shows like Mad Men as rejuvenated forms of the pleasing bestseller. The episode is named 'Indian Summer', surely a reference to the opening line of the era's most pleasing and husky nominee, Grace Metalious' Peyton Place, which famously begins: 'Indian summer is like a woman. Ripe, hotly passionate, but fickle, she comes and goes as she pleases so that one is never sure whether she will come at all, nor for how long she will stay.'1

Gordon Hunter has noted that the 'critical scorn' with which 1950s novelists like Metalious have been remembered is a perpetuation of the judgement of their contemporary critics who 'derogated the way '50s novelists tried to come to terms with the postwar era', a scorn 'for their efforts to register and confront the way we lived then'.2 He catalogues Metalious with Sloan Wilson, whose Man in the Gray Flannel Suit is an obvious precursor of Mad Men as Melissa Gregg argues elsewhere in this collection. The episode returns to the figure of the 'ripely passionate' woman at its end, when Betty Draper finds her washing machine, paired with an active imagination, another contraption whose implication in regimes of feminine regulation and sequestration can be profitably diverted into even more private realms of positive feeling. Implicit in the title is the suggestion that how one feels is not always a product of deep interior desires but rather can be generated by a surprising revision of the familiar; female orgasm, in particular, can be associated not just with the kinds of complicated social rituals that bind sexual partnerships but rather more simply elicited through mechanical, labour-saving devices. Pleasure is potentially everywhere, and impossible to police.

Peggy's copy was repurposed by Mark Greif in his 2008 article, 'You'll Love the Way It Makes You Feel', which reviewed the release of Mad Men's first season on DVD and in tones that reproduced the contemporary 'critical scorn' reserved especially for the suspiciously pleasing. For Greif the stimulation of feeling is nothing so simple, nor anything so devoid of complicated social ritual. In Greif's account the driving social engagement of the series is historical: he conceptualises 
the series in terms of the way it elicits feelings from one generation to another, referring to it as 'an unpleasant little entry in the genre of Now We Know Better': We watch and know better about male chauvinism, homophobia, antisemitism, workplace harassment, housewives' depression, nutrition and smoking. We wait for the show's advertising men or their secretaries and wives to make another gaffe for us to snigger over. 'Have we ever hired any Jews?'-'Not on my watch.' 'Try not to be overwhelmed by all this technology; it looks complicated, but the men who designed it made it simple enough for a woman to use.' It's only a short further wait until a pregnant mother inhales a tumbler of whisky and lights up a Chesterfield; or a heart attack victim complains that he can't understand what happened: 'All these years I thought it would be the ulcer. Did everything they told me. Drank the cream, ate the butter. And I get hit by a coronary.' We're meant to save a little snort, too, for the ad agency's closeted gay art director as he dismisses psychological research: 'We're supposed to believe that people are living one way, and secretly thinking the exact opposite? ... Ridiculous!' - a line delivered with a limp-wristed wave. Mad Men is currently said to be the best and 'smartest' show on American TV. We're doomed. ${ }^{3}$

When I first read Greif's article it made me feel ... unconvinced, and I read it as an example of another unpleasant micro-genre, 'here we know better', reassigning its temporal consignment of distant judgement (the present judging the past) to a spatial relation, American TV subject to judgement 'over the pond' (Greif is American but the place of publication is of interest here). Perhaps I found it unconvincing because I knew that the 'not on my watch' comment quoted above was ironic and clearly marked as such, that the bald enunciation of a closet epistemology by Salvatore, who is not precisely a 'closeted gay art director' (this identification is anachronistic) was structured to permit a relation of empathy, not elicit 'a little snort' (even if Greif did snort). Perhaps I felt bemused because I had always watched the series with a strong sense that its orientation toward 'now' was as the 'poisoned fruit' of the historical tree, rather than as its soothing remediation. Greif's take was puzzling. Perhaps I wanted to be left alone to love the way it makes me feel. As a long-time soap opera aficionado Mad Men's deployment of stock character and bald, 
apparently banal commentary seemed to me anything but simple; rather than taking these flattening structures as symptoms of historicising schadenfreude I read them generically, and understood them as place-holders that will inevitably, perhaps programmatically, repulse an audience for whom televisual tact, massaged into an entirely fantastic historical register or else nuanced as a form of vestigial 'high culture', is the essential ingredient in their middlebrow appreciation of the mode. Mad Men never permits its audience the fantasy that it is entirely outside the purview of television in its daytime, domestic mode, that it is, in other words, simply "quality" television. Greif is concerned that Mad Men is 'said to be the best and "smartest" show', and seeks to demonstrate that it's stupid-stupid, like soap. Without 'tact', television is ... just television, and worse, what Greif describes as 'a toybox of tin stereotypes' and 'soap opera antics of bed-hopping and keeping secrets'. Those 'soap opera antics', Greif worries, are only intermittently interspersed with other kinds of action, a 'dramatic process' that is 'desultory' and 'distracts only a little' from the soap of the series.

Describing a prime-time drama as 'soap' implies that the fans of Mad Men have been gulled by a kind of kitsch, seeing in the contours of the show-its careful attention to period style, its references to the death drive, avant-garde poetry, European cinema-the appurtenances of highbrow culture sold in a debased, derivative modality. Kitsch, a slippery term, has at its heart a misappropriation of the high aesthetic in service of the culture industry and its passive, consuming audience, and what better realisation of such a sleight of hand than in the aestheticisation of the advertising industry mid-century, a solipsistic formulation, reconciled with vulgar sentimentality, the sheer banality of 'loving' how one feels in the hands of this commanding machine. Contemporary viewers score an illicit or illegitimate sense of superiority by viewing stereotypical representations of the past, and those representations, furthermore, are illegitimately historical. They register the work of thinking as 'desultory', in favour of more mechanical pleasures: Peggy and her Rejuvenator. Just as the contraption associates copy and a simulated (read inauthentic) pleasure, so too does Mad Men 'rejuvenate' period to elicit mechanical satisfaction.

As Don Draper is reminded in the first episode, 'Ladies love their magazines', and it is the access ladies have to these debased forms of pleasure-generation that 
links Greif's critique to the gender politics of the show. Ladies also love their soaps, and their Rejuvenators: a familiar catalogue of denigrated consumption forms the scaffolding of Greif's critique and equally demonstrates that the kinds of offhand derogations the show flaunts as its period marker are equally anachronistic indices of contemporary snobbery. After Adorno, Calinescu defines kitsch most succinctly as 'the parody of aesthetic consciousness' and Greif's anxiety over the pleasure of Mad Men's audience arises, I think, from an anxiety over the very legitimacy of its taking pleasure in television, especially when watching a television program that arrives with the promise of belonging to the recently commodified category of 'quality television'.4

Another way of putting this would be to ask if the disarticulation of 'quality' television from its debased precursors (in particular soap opera) performs a critical function in its reanimation of arguments about 'quality' that were originally made mid-century about books like Peyton Place, and which reappear in such venues as the London Review of Books precisely because an anxiety about demarcating a failure of quality (that is, that Mad Men isn't highbrow) actually organises its thinking around the middle and lowbrow axis. As Jane Feuer notes, the opposition of 'quality' and 'trash' television 'goes back to the very beginning of US television programming', when the quality of 'live anthology drama' was pitted against 'emerging forms of series TV'.5 Mad Men returns debates around middle and highbrow to their original mise-en-scène, chronicling the revision of mid-century domestic decoration as modernist interior 'architecture', the revision of wordy advertising copy as elite graphic design, the 'streamlining' of feminine sexual pleasure away from complicated social arrangements.

These reanimated debates define or haunt arguments about the series' historical decorum and the use of period markers to plot out contemporary notions of the past, and the traffic between these two areas of anxiety forms the argument here, which is that a hallucinatory apprehension of the past-anachronistic, temporally confusing, overtly displacing documentation while imitating its modefacilitates such traffic. That these contests are parsed in terms of gender is abundantly clear in the series' recourse to high art; Draper is drawn to the hip and modernist poetics of Antonioni and O'Hara (Frank, not John) but as Kieron Clark notes, 'Betty's world, by contrast, is a little more Douglas Sirk than Michelangelo 
Antonioni'.6 As the revisionist understanding of Sirk undertaken at least since Fassbinder demonstrates, these 'contrasts' are anything but obvious, and their demarcation requires a hallucinatory logic.

Those things that are taken to characterise 'quality television'-narrowcasting, novelistic story-telling, 'depth' of characterisation, plot complexity, realism and so forth-have always been ingredients in prime-time television, and have certainly characterised the leading edge of drama since the 1960s in Anglophone television culture. At the same time, as I will discuss below, the 'branding' of 'quality television' in the 1990s and 2000s, mostly achieved through its association with cable networks, has its own agenda of historical 'rejuvenation', redefining what was already a significant aspect of television programming as a brand new 'feeling'. Most self-evidently, though, 'quality' television can only own the category if it explicitly avoids the most explicitly lowbrow characteristics of its non-quality competitors: for comedy that means no laugh track, and for drama that means no soap. Janice Radway's wonderful book on the Book-of-the-Month Club, A Feeling For Books, offers a simple formula for distinguishing between low and middlebrow as they stood mid-hcentury, the cultural time being mimed in the series. Radway comments that within publishing:

Sections of the industry ... had adopted the logic of modern mass production. They had installed corporate creation and managed distribution at the center of their enterprises in order to increase the flow of commodities for the market. Within this system, publication was conceived of as an endless process of circulation and cultural recycling, a reformulation and ever-widening distribution of previously existing material. Predictably, these operations were tarred with powerful epithets and dismissed as entertainment by champions of the author and the mode of production of which he was perhaps the defining element. The category of the lowbrow was understood to include all standardized cultural objects that were generated through a corporately organized mode of production, including moving pictures, radio programs, and pulp novels. The space of the middlebrow was occupied by products that supposedly hid the same machine-tooled uniformity behind the self-consciously worked mask of culture. The evaluative geography of the high, the low, and the middle, it 
would seem, was mobilized specifically at this moment to control the temporal ascendancy of new, highly threatening productive forces. ${ }^{7}$

In his 2005 book From Lowbrow to Nobrow, Peter Swirski observes that 'there are few reasons to believe that popular fiction has a lasting harmful effect on highbrow literature'; Swirski's book argues that 'distinction between "brow" cultures is a dead issue'. ${ }^{8}$ Many of us might find this an unremarkable observation, but Swirski's contention is that the virulence with which television is still treated in the media suggests that anxieties over brow cultures still arise. In particular, an anxiety about the medium's ability to escape the 'middlebrow' has supplanted the more predictable antagonism historically posed between high and low. Mad Men's status as middlebrow object is difficult to contest, but interesting precisely because of the way the series identifies and aestheticises the regimes of technological reproduction by which an historical determination of the current state of the brows can be made. In other words, to identify Mad Men as middlebrow is both inevitable and also misleading, because of its very concerted attention to the technological operations of its own production, and the technological production of structures of personality and feeling that animate the show. This article follows the suspicion that a series of historicisms animate Mad Men's mid-century presentation of the 'space of the middlebrow ... occupied by products that supposedly hid the same machine-tooled uniformity behind the self consciously worked mask of culture'. These include its documentation of historical time, its interest in the representation of historical change as formal imposture, and its introduction of questions of technological reproduction at the heart of its representation of historicity.

It's interesting, then, that while the series' rationale implicates the pleasure of women, women experience so little pleasure in the series itself. Peggy's startling encounter with the Rejuvenator is one of a handful of scenes where pleasure is made available to her. In an interesting reversion of an expected trope, in Mad Men feminine pleasure becomes the mechanically predictable or productive sign of the lowbrow masked by self-conscious masculine angst. What women want, for these mad men, is all too predictable. Just as popular women's novels such as Peyton Place were perceived mid-century as threats to the edifice of literary culture, feminine predictability in all its endless iterations challenges the evolution of their work from middle to highbrow. This drama is epitomised in the fate of Kenneth Cosgrove, 
whose short story in The New Yorker remains a blip on the screen in the face of the demands of home and the drive of advertising toward a feminine repetition. The middle, as famously noted by Leslie Fiedler in 1955, is 'against both ends'. 9

In the first episode of the first season of Mad Men, Don Draper, confronted with a document that exactly reproduces one he's just jettisoned, notes dismissively that there is no 'magic machine' that can make exact copies of things. Draper's comment in the context I have just outlined can be taken to gesture to the possibility of the 'author' in the midst of all this duplication-his status as inimitable advertising auteur is a driving engine of the first season-and a belief in the unreproducible author concerts a belief in high art. Equally, though, it signals a certain kind of blindness with which he is afflicted, a lack of vision predicated on the closeness of the future to any particular predicament. Don's enabling blindness is given narrative girding when we learn that he is himself a fake, the product of a 'magic machine' that has enabled his, Dick Whitman's, own arrival in the world as the 'exact copy' of the original Don Draper. His ongoing imposture makes the contemplation of what may be looming on the horizon always compromising: the next thing might always be the last thing, the collapse of his ongoing fraudulence. The metempsychosis that structures the series-the transmogrification of Dick into Don-is as unstable as its complementary historicism, which make temporal borders disturbingly porous.

Draper's comment also proleptically introduces the star of the second season, a photocopier that appears to be a 'magic machine' that makes exact copies. The appearance of the 'magic machine' makes his words simultaneously prophetic and redundant, a double-faced version of history that is laced throughout Mad Men. Draper's role in the series is as a mundane avatar for Benjamin's avenging angel with his back turned to the future 'while the pile of debris before him grows skyward'.10 The item that has magically reappeared as its own double, 'magically machined' back into the future, is a document he recently tipped into the trash, a treatise on the death drive and its relationship to smoking that he finds an unhelpful contribution to a campaign for Lucky Strike. An item rescued from trash becomes in the future its own 'exact copy', an initial allegory for the fate of the series itself as it went through various trashings before its debut in May 2007. But this historical hingeing, routed through the materiality of the photocopier, offers an orientation toward the diegetic future of the show as a backward glance at the past. It reminds 
the viewer of this ambitious series that it promises intricate associations between past, present and future, and the series' history and contextual moment suggests its oscillation between past, present and future constitute a particular form of modernity such as that proposed by Svetlana Boym as an 'off-modern'. Mad Men troubles a critique of its nostalgic mode by troubling the possibility of fixing the way in which its periodisation operates: as satire, as nostalgia, or as 'exact' reproduction. It makes that argument by considering the way in which the series negotiates its generic and modal antecedents, film and print, to frame its representation of historical movement.

- The CARousel

Matthew Weiner, Mad Men's creator, was a writer and producer on seasons five and six of the critically acclaimed HBO series The Sopranos, and while it might at first seem strange to link the two series thematically as well as historically, there are similarities. Like Mad Men, The Sopranos offered an opportunity to think through such questions as the role of executive judgement, the relationship between intimate life and professional life, the movement from the city to the suburbs, questions that are central to a consideration of middle-class American life in the second half of the twentieth century. In The Sopranos, we are (in all likelihood) estranged from its characters not by the passage of time but by virtue of their most common occupation, serving in some way the diffuse networks of organised crime on the eastern seaboard. Another intra-diagetic distancing is effected by the plotting of a mob dynasty away from the familiar televisual landscape of Manhattan, as Tony Soprano negotiates on behalf of, and sometimes heads, the New Jersey family. Their purported occupation is 'waste management', a profession that is sustained by the effluvium of late capital's consumption culture, dealing with the residue of a market economy fuelled by the machinations of Weiner's Mad Men.

Weiner reports that he had some difficulty before finding a home for the series at the cable channel American Movie Classics (AMC). The shifting nature of television production in the United States over the last decade is implicated in the fate of these two shows. The Sopranos became one of a number of HBO shows associated with the reinvention of 'quality' commercial television for a new audience. Being broadcast on cable allows for certain kinds of liberties in the 
representation of, among other things, sexuality, language and violence, and the rise of HBO drama was emulated by the cable network Showtime. HBO and Showtime are responsible for Sex and the City, The Sopranos, The L Word, Deadwood and other shows that pressured the assumed boundaries of permissible televisual representation as they were defined by the networks. HBO went so far as to have a brand identifier the phrase 'It's not television, it's HBO', and in complementary formation its trace may be found in network shows such as 30 Rock, understood to bear a resemblance as much to a cable aesthetic as to network programming.

Mad Men was the first original series developed by AMC, a cable network otherwise devoted to movies. Its production there highlights this transitional space that arose in the 1990s, where what was considered appropriate for television becomes less clear, and cable networks allow some formal and thematic experimentation. AMC has since produced the critically acclaimed series Breaking $B a d$. The repurposing of AMC, a movie channel, as a venue for original series hints at another televisual transmediation, where televisual representation joins the cinematic in a shared venue. Mingling with AMC's catalogue of 'classic' movies, Mad Men conforms to its ethos of nostalgic archiving. Not merely because it is a period drama but perhaps even more because it is self-consciously interested in the fantastic revisiting of period time and place, Mad Men supplemented the vanguard logic of HBO and Showtime with its secondary revision of the look and feel of 'quality' television. The closing episode of the first season, 'The Wheel', narrates such a process of revision when Don Draper reinvents the slide 'wheel' as the 'carousel', a vehicle for screening the moving image that articulates two technologies, the photographic slide and cinema, just as the series itself is a nodal point in the articulation of cinema and television. The episode offers a quasiacademic rationale for the slideshow as a vehicle for nostalgia, a term for which Don offers etymological context and which anticipates the bawling of his audience as he uses the slide 'carousel' to join segmented parts into a cinematic whole:

Nostalgia means 'the pain from an old wound'. It's a twinge in your heart far more powerful than memory alone. This device isn't a spaceship, it's a time machine. It goes backwards. Forwards. It takes us to a place where we ache to go again. 
Svetlana Boym writes of what she calls the 'off modern', a 'lateral move', a 'detour into some unexplored potentialities of the modern project'. 11 Such a detour is provided, for instance, by the photographs of Lartigue who 'wanted to make photography do what it couldn't do: to capture movement. The blurs on the image are photographic errors, nostalgia for what photography could never be, longing for cinema'.12 This identification of photography as a medium 'longing' for its historical future suggests both that the 'longing' of a nostalgic feeling may be equally directed toward the future as toward the past, and that such a desire, for what can be captured, be it by the photocopier or the carousel, offers media their particular momentum. It also permits a re-orientation to the circus of media out of which Mad Men arose: cinema, certainly, but also the novel and the short story, literary forms that contextualise the writing of copywriters in the series. The 'longing' photograph may find its mechanical remediation in the carousel, a televisual midpoint between its own technology and the cinematic. The carousel mechanically animates the photograph precisely as the slides revise the material, paper object as a translucent, celluloid, 'as if' cinematic fragment. This longing pivots the advertising copy and its revision of the wheel, 'reinvention' of the wheel, as a gesture to the future instantiated in the relay of similar images across diverse media.

-THREE FACES

HBO television epitomises the middlebrow according to Radway's formulation; its surreptitious cinematic format assures its audience that it's 'not television' and in its most ambitious shows, such as The Wire, the 'self-consciously worked mask of culture' is everywhere in evidence. Mad Men, consigned to the AMC channel, occupies a mid or equivocal point between the amply middlebrow workings of a show like The Wire and the lowbrow. Its self-consciousness is directed not to the 'workings of culture' but the workings of technology. In the first episode of the second series, the appearance of a photocopying machine, proleptically signalled by Don Draper's dismissive comment that there is no 'magic machine' that can make exact copies of things, bears further scrutiny.

There is, in fact, a 'magic machine' that does just that, and the 'things' it imagines are people. The problem of 'two faces' was marked as pathological by Hervey Cleckley in his 1941 The Mask of Sanity, where the kind of impersonation 
Dick perpetrates is given a psychological genealogy co-extensive with a particular masculine subjectivity: white, middle-class, managerial in its relation to personality. ${ }^{13}$ The 'mask of sanity' offers regulation to the disorder that lies beneath, rather as the 'self-conscious mask of culture' organises middlebrow claims for distinction from the low. Such a formulation, which promotes the opposition of depth and surface, authentic and inauthentic, real and imposter, artificial and integral, reproduces in a popular psychological register the kinds of arguments made for television programs as properly or improperly 'quality' or 'trash', or, in another register, 'television' and 'not TV' (HBO). But the problem of quality or brow remains stubbornly one with three interlacing levels to distinguish: high, middle and low. So in the logic of my analogy it's entirely appropriate that over a decade later Cleckley collaborates with Corbett Thigpen to write a popular bestseller that assists in the amplification of 'faces' from two to three. The Three Faces of Eve 'popularises' the serious work of psychological profiling found in The Mask of Sanity by outlining the contours of 'multiple personality' in the form of a case study (women love their case studies). ${ }^{14}$ While The Mask of Sanity identified a distinction between depth and surface in the persona of the masculine psychopath-as-imposter, The Three Faces of Eve evangelised a contemporary diagnosis of 'multiple personality disorder', as an experience of high, low, and in-between authenticity via the three personae presented in the case study, who are rarefied (Eve White), trashy (Eve Black) and in between (Jane). The condition of multiplicity framed in the 1957 film version of The Three Faces of Eve is a problem with technological resonances as its case-study pretensions (as self-conscious mask, pace Radway) do not inhibit but even perhaps foster the book and film becoming popular classics and spawning similarly lowbrow iterations. Flora Reita Schrieber's Sybil, whose 1976 telemovie adaptation features the original Eve (Joanne Woodward), ascended from the position of patient to therapist (a year earlier Johnson directed the screen version of The Man in the Gray Flannel Suit). ${ }^{15}$ It's an historical progression that mimes generative characterological transmogrifications such as those that abound in Mad Men. A middle-class, masculine condition is amplified from the status of a double to the condition of a multiple: this condition becomes a problem to be confronted on several 'sides', not just front and back (original and copy) but in seriality: front and back, and in- 
between. Mad Men isn't just about the pairing of men with their madnesses, but requires adjustment to locate its intermediary women.

Mad Men's relays between 'now' and 'then', characterised by Greif as a contemptuous preference for the present moment, are likewise triple. Its first series moves between three periods: the 2000s, the 1960s and the 1930s. Understanding the series only in terms of 'then' and 'now' is seriously misleading, reducing its complex configurations of threes into more manageable albeit agonistic pairs.

Whereas Greif identifies the contemporary as a point of cultural superiority, the credits suggest otherwise as they situate contemporary culture as resolutely traumatised, 'urged' to repeat an experience of the fall into death marked by images that metaphorise the falling man photographs that briefly circulated after $9 / 11$ and were later memorialised in documentary form. Gary Edgerton writes that 'Mad Men's perspective is resolutely post-9/11. This vantage point is not just chronological; it is psychic and visceral.' Edgerton suggests that the incorporation of the 'falling man' images plots Mad Men into a succession of citations:

After appearing in hundreds of newspapers right after 9/11, the Falling Man image was airbrushed from history as being too callous and inappropriate to be seen. It probably forced people to confront head-on the full life-and-death implications of $9 / 11$ too soon after the event, including their own mortality. That being said, the highly-charged perceptions evoked by the Falling Man image cannot be suppressed forever. It has already found its way into Eric Fischl's sculpture, Tumbling Woman (2002), Henry Singer's documentary, 9/11: The Falling Man (2006), Don DeLillo's novel, Falling Man (2007), and now Mad Men's opening sequence (2007- ). ${ }^{16}$

Edgerton's declensions mark a similar fall, a fall in cultural capital from the sculpture to the documentary, from the novel to the television series. Just as the report on the death drive can be fished from the trashcan and recycled again, as if there were a 'magic machine' that makes 'exact copies', so too can the repressed images of the 'falling man' be recycled in an urge to repeat that spirals down into familiar and safer tracks of brow culture.

The first season's fascination with the 'death drive' is given a form of 'signage' in these images, and 'signage' becomes the season's lead trope for its identification 
of the power of historical pull; in the episode most concerned with the 1930s, 'The Hobo Code', nascent homosexual Sal notes that his interest in Manhattan architecture is organised by a particular professional preference, an interest in signage. This aesthetic preference, one that operates to indicate other preferences, elicits a romantic offer Sal anxiously declines. Signage appears in parallel scenes of the episode when Don re-encounters in dream-structure his 1930s' childhood where a visiting hobo describes to Don the 'Hobo Code', a secret language that proleptically figures Sal's coded sexuality. Signage is a form of outsized, outdoor coding. It marks, at the least, the place of the threshold between home and away (the code incised on the fence post), the closet as such a threshold space, and the office door as a mark of privileged sequestration. The episode offers a triangulation between Sal, Don's father and Don himself as Don is restored from his reveries (unarguably anti-nostalgic in their reversion to past scenes) to his contemporary, name-on-the-door office; the sign for a dishonest man is transmogrified as the sign of Don's (dishonest) name. This series of associations mimes the traumatic descent into memory that presages Don's recollection of the hobo, and the falling man of the credits; the traumatic vista of futurity offered to Sal is, like 9/11, a robustly anticongratulatory representation of the present or near-present.

The ubiquity of smoking in the series has been an issue around which critical commentary has been ambivalent, and often encountered in the logic of 'we know better now'. Smoke operates as a pervasive metaphor for the impossibility of proper historical representation, and so the impossibility of charting accurate trajectories from there to here spatially, temporally, affectively. The first episode of the first season is named after the song 'Smoke Gets in your Eyes', and the song's implication, that the shedding of tears can be given a casual alibi, returns to the casual alibis that frame Don's adoption of his fraudulent identity. Smoke in the eyes becomes a shorthand figure for the problem of proper perception: in the song's lyric, it's the smoke (the alibi) that tells you how to 'know' what is 'true'. Smoke is a trace for the factual-historical, which leaves its remnant in the form of 'daily residue' but also as a permanent blur of perception (the 'photographic' blur, anticipating future remediation, the 'off-modern'). The version of 'Smoke Gets In Your Eyes' that features in the opening scene of the show was released in 1958, a cover of a song that was famous from Depression years; a tune that ostensibly locks us into the 
contemporary diegesis of the scene in fact already carries the residue from the 1930 s that 'gets in your eyes'.

This title gives us some sense of how time and period will be accounted for in Mad Men. The series ostensibly represents the 1960s in terms of representational integrity; that is, it makes spectacular references to its own period, foregrounded and parodic-kitsch. 'Smoke' in your eyes is a figure for passing off melancholy as a physical irritant, and the series' opening with this song reworks this motif of passing as a form of audio-visual integration: an African-American crossover hit provides the soundtrack for the opening scene where Don Draper converses with an AfricanAmerican waiter in an old-fashioned bar. Indeed, the bar is a slightly re-dressed Lenox Lounge, and while its identity as such is attenuated (it is not, in the episode, an African-American haunt), this motif of passing is registered in the mise-en-scène. In his commentary on this first episode, Matthew Weiner notes that 'we're in an art deco environment which is not 1960 but I wanted to establish that everything that existed before 1960 still existed' ${ }^{17}$ Mad Men's tripled structure animates then both the infancy of its lead characters, their formative 'depression', but also 'everything that existed', a formulation that has both phylogenic and ontogenic implications. The opening sequences of the episode grounds us in two different directions, pointing away from the 'present moment' of the diegesis. The credits close by showing us the back of Don Draper's head, and the show opens with its first shot settling on-the back of Don Draper's head. This is a position that suggests an orientation we share as viewers, a perspective we are taking on, as though he's sitting in the seat in front of us at the movie theatre. And what is he looking at? The future or the past?

On the logic of Don's prophetic foreclosure that I discussed at the beginning of this article, and on the logic of the shot itself, he has his back to the present moment, the future, as he contemplates the past. The Lenox Lounge is located in Harlem, a setting where we would almost certainly not find Don Draper (his bohemian jaunts are located in the Village). It's not there to reference race explicitly, but to 'pass' as another location, as a period recreation of a Manhattan bar. The first exchange of the program, between Don and the waiter, animates a sense of historical past by exploring prejudice: against African-Americans, and against women. This is the scene from which the phrase 'ladies love their magazines' is drawn, and in his commentary Weiner notes that the conversation between the two men promotes 
'this feeling of sort of fun and camaraderie. These men can bond on [sic] the fact that they both think very little of women even though there's this race issue'.18 Their homosocial pairing relies on a more conventional triangulation than that afforded by signage, casting Don and the waiter in a homosocial relation pivoted around the women of which they think so little, and it locates race, gender and value as the terms that circulate in this exchange. Although its 'art deco' frame and actual location might lead us to understand the issue here as one of 'passing' the problem of the mask, of duplicity, becomes another iteration of the problem of three.

-RELAX

Rather than offering a model of recollection as self-affirming, Mad Men offers hysterical reminiscence, the movement of the mind to the past in terms of points of trauma that can offer affective contact with 'past selves'. This orientation is epitomised in its evocation of Freudian analysis, where Betty finds herself triangulated both by her therapist (who is on the phone to Don) and by the triple historical structure I have mentioned, embedded in therapy on the Barcelona day bed, an 'antique' form introduced in the1930s but charged with new meaning as mid-century decor. Traumatic reconfiguration inflicts a form of nostalgic wound that cannot be eased through aesthetic comfort because of the way in which its technological logic is foregrounded: the tears elicited at the end of the last episode by Don's narration is not merely supplemented by the carousel, but also made explicitly technological; no aesthetic sublime, no transcendence, rather the repeated revisitation of traumatised pasts. In the same way the traumas of the 1930s resonate in the show's 1960s (and are refracted through World War II in the figure of Roger Sterling), our contemporary moment's own trauma-systemic sexism, racism, risk, risk-anxiety, desire to disguise manufacture as craft-are the matter of the show, except for those (like Greif) too enrolled by the contemporary moment to feel it.

In the final episode of the first season of Mad Men, Don's pitching of the wheel as carousel is intercut with the taping of an advertisement. The Rejuvenator has been renamed the Relaxiciser and Peggy is instructing Annie, the voice model, to 'perform' herself: 'You're back to being you-right now', Peggy instructs Annie, who replies: 'I don't understand-I am being me' and breaks into tears. Annie's repetitions of style convert cliché to melodrama; her 'three faces' (me, 'me', 'back to 
me') restate the complexity of Mad Men's representational strategies, where 'real feeling' is elicited by the failure to perform feeling. Because the session is filmed we see what the words do not convey, the reception of the message in the moment of its technological production. Far from loving the way it makes you feel, the Relaxerciser returns us to distress. Precisely as passing orients the series' critique of the discourse of the 'greatest generation', celebrated in the United States as braver, more ethical, more worthy than the present lot, by suggesting that generation was beset by its own problems of authenticity, authentic feeling itself only arises as a form of signage. That logic extends from the series' formulaic debunking of the feeling elicited by advertising, to its distance from a middlebrow re-coding of television as authentic 'high' culture. Don't trust the way you feel. Psychological effect, in the case of Annie, is generated not by an assumption of surface and depth but rather by the traumatising effects of channelling signage, words writ large with injurious consequences. Perhaps it is this damage that critics of the series wish to forestall, but in the logic of the series, it's already happened.

Melissa Jane Hardie teaches in the English Department, University of Sydney. Recent publications include an article on Kitty Genovese and chapters on Djuna Barnes and the editing of modernist texts, Law and Order: SVU and its fans, and Lindsay Lohan and her closet.

\footnotetext{
-NOTES

1 Grace Metalious, Peyton Place, Northeastern University Press, Lebanon, 1999, p. 1.

2 Gordon Hunter, What America Read: Taste, Class, and the Novel, 1920-1960, University of North Carolina Press, Chapel Hill, 2009, p. 285.

3 Mark Greif, 'You'll Love the Way It Makes You Feel', London Review of Books, vol. 30, no. 20, 2008, <http://www.lrb.co.uk/v30/n20/mark-greif/youll-love-the-way-it-makes-you-feel>.

${ }^{4}$ Matei Calinescu, Five Faces of Modernity: Modernism, Avant Garde, Decadence, Kitsch, Postmodernism, Duke University Press, Durham, 2003, p. 240.

5 Jane Feuer, 'HBO and the Concept of Quality TV' in Quality TV: Contemporary American Television and Beyond, ed. Janet McCabe and Kim Akass, IB Tauris, London, 2007, p. 146.
} 
${ }^{6}$ Kieron Clark, 'At The Movies with Don Draper', Matinée Idle,

<http://matineeidle.wordpress.com/2010/03/21/at-the-movies-with-don-draper/>.

7 Janice Radway, A Feeling For Books: The Book-of-the-Month Club, Literary Taste, and Middle-Class

Desire, University of North Carolina Press, Chapel Hill, 1999, p. 222.

8 Peter Swirski, From Lowbrow to Nobrow, McGill-Queen's University Press, Montreal, 2005, p. 61, back cover.

9 Leslie Fielder, 'The Middle Against Both Ends' in Arguing Comics: Literary Masters On A Popular

Medium, ed. Kent Worcester and Jeet Heer, University of Mississippi Press, Jackson, 2004, pp. 122-33.

10 Walter Benjamin, 'Theses on the Philosophy of History' in Illuminations, trans. Harry Zohn, Schocken Books, Berlin, 2007, p. 258.

11 Svetlana Boym, Architecture of the Off-Modern, Princeton Architectural Press, Princeton, 2008, p. 74.

12 Ibid.

${ }^{13}$ Hervey M. Cleckley, The Mask of Sanity: An Attempt to Clarify Some Issues About the So-Called

Psychopathic Personality, Mosby, St Louis, 1950.

${ }^{14}$ Corbett Thigpen and Hervey M. Cleckley, The Three Faces of Eve, Pan Books, London, 1960.

15 The Three Faces of Eve, dir. Nunnally Johnson, Twentieth Century Fox, 1957.

16 Mark Edgerton, 'Falling Man and Mad Men', In Media Res: A Media Commons project,

<http://mediacommons.futureofthebook.org/imr/2009/04/19/falling-man-and-mad-men-154>.

17 Matthew Weiner commentary, Mad Men, season 1 DVD set, AMC, Lionsgate, 2007.

18 Ibid. 